\title{
Inhibition of Osteoclast Differentiation by Carotenoid Derivatives through Inhibition of the NF- $\kappa$ B Pathway
}

\author{
Shlomit Odes-Barth ${ }^{1, \dagger}{ }^{\dagger}$, Marina Khanin ${ }^{1}$, Karin Linnewiel-Hermoni ${ }^{1, \pm(\mathbb{D}, \text { Yifat Miller }}{ }^{2,3}$, \\ Karina Abramov ${ }^{2,3}{ }^{1 D}$, Joseph Levy ${ }^{1}$ and Yoav Sharoni ${ }^{1, *}$ (D) \\ 1 Clinical Biochemistry and Pharmacology, Faculty of Health Sciences, Ben-Gurion University of the Negev, \\ Beer-Sheva 84105, Israel; shlomitbarth@post.bgu.ac.il (S.O.-B.); hanin@bgu.ac.il (M.K.); \\ Karin.Hermoni@lycored.com (K.L.-H.); lyossi@bgu.ac.il (J.L.) \\ 2 Department of Chemistry, Ben-Gurion University of the Negev, Beer-Sheva 84105, Israel; \\ ymiller@bgu.ac.il (Y.M.); karinaab@post.bgu.ac.il (K.A.) \\ 3 Ilse Katz Institute for Nanoscale Science and Technology, Ben-Gurion University of the Negev, \\ Beer-Sheva 84105, Israel \\ * Correspondence: yoav@bgu.ac.il; Tel.: +972-52-483-0883 \\ + Deceased. \\ $\ddagger$ Current address: Lycored, Secaucus, NJ 08876, USA.
}

Received: 12 October 2020; Accepted: 20 November 2020; Published: 23 November 2020

check for updates

\begin{abstract}
The bone protective effects of carotenoids have been demonstrated in several studies, and the inhibition of RANKL-induced osteoclast differentiation by lycopene has also been demonstrated. We previously reported that carotenoid oxidation products are the active mediators in the activation of the transcription factor Nrf2 and the inhibition of the NF- $\mathrm{kB}$ transcription system by carotenoids. Here, we demonstrate that lycopene oxidation products are more potent than intact lycopene in inhibiting osteoclast differentiation. We analyzed the structure-activity relationship of a series of dialdehyde carotenoid derivatives (diapocarotene-dials) in inhibiting osteoclastogenesis. We found that the degree of inhibition depends on the electron density of the carbon atom that determines the reactivity of the conjugated double bond in reactions such as Michael addition to thiol groups in proteins. Moreover, the carotenoid derivatives attenuated the NF- $\mathrm{kB}$ signal through inhibition of IкB phosphorylation and NF- $\mathrm{kB}$ translocation to the nucleus. In addition, we show a synergistic inhibition of osteoclast differentiation by combinations of an active carotenoid derivative with the polyphenols curcumin and carnosic acid with combination index $(\mathrm{CI})$ values $<1$. Our findings suggest that carotenoid derivatives inhibit osteoclast differentiation, partially by inhibiting the NF- $\mathrm{KB}$ pathway. In addition, carotenoid derivatives can synergistically inhibit osteoclast differentiation with curcumin and carnosic acid.
\end{abstract}

Keywords: apo-carotenals; lycopene; polyphenols; bone; osteoclasts; NFkB; synergy

\section{Introduction}

Several epidemiological studies imply that fruit and vegetable consumption decreases morbidity and has a beneficial effect on bone health [1-3]. Carotenoids, a major group of micronutrients in a fruit and vegetable-rich diet, are fat soluble and pigmented phytochemicals produced by bacteria, fungi, algae, and plants [4]. From the more than 600 natural carotenoids that have been identified, nearly 50 are consumed by humans [5], whereas about 20 appear in human tissues and blood [6]. $\beta$-carotene, lycopene, and lutein compose the major plasma carotenoids [7]. Lycopene is derived mainly from tomatoes and tomato products, and its content in tomatoes is $0.7-20 \mathrm{mg} / 100 \mathrm{~g}$ wet weight [8]. The sources of other carotenoids are more diverse; for example, $\beta$-carotene is rich in orange-yellow 
vegetables and fruits, but it is also found in leafy vegetables. Humans appear to absorb carotenoids in a relatively non-specific fashion and, thus, their plasma and tissue concentrations reflect their individual dietary habits [7]. The relative abundance of each of the five major carotenoids in the diet are similar to their distribution in plasma.

The role of carotenoids has been investigated in epidemiological and interventional studies. Lycopene supplementation to postmenopausal women for four months significantly decreased oxidative stress parameters and the bone resorption marker n-telopeptide of type I collagen. This was accompanied by a significant increase in serum lycopene. Most adult bone diseases are due to excess osteoclastic activity, which results in an imbalance in bone remodeling which favors resorption by osteoclasts over building by osteoblasts [9]. Animal and cellular studies on the role of fruits and dietary phytochemicals in bone protection were reviewed by Shen et al. [10]. An in-vivo study showed that a supplement containing tomatoes improved bone health in ovariectomized osteoporotic rats [11]. The effect of carotenoids on bone has also been studied in cell culture. Rao et al. showed that the carotenoid lycopene stimulates osteoblast cell proliferation and alkaline phosphatase activity in SaOS-2 cells, inhibiting osteoclast formation and mineral resorption mediated by reactive oxygen species in cells from rat bone marrow [12,13]. Costa-Rodrigues et al. studied the effects of lycopene on differentiation and function in human osteoclasts and osteoblasts. They found that lycopene decreased osteoclast differentiation and resorbing activity, and increased osteoblast proliferation and differentiation [14]. Using signaling inhibitors, they tried to identify the pathways involved in lycopene action but were unable to show an effect on NF-KB in osteoclasts even though such an effect was found in osteoblasts.

Identification of the osteoclastogenesis inducer, RANKL, expressed mainly in osteoblasts; its cognate receptor, RANK, expressed on osteoclast progenitors; and its decoy receptor osteoprotegerin has contributed to understanding of the molecular mechanisms of osteoclast differentiation and activity [15]. One of the early molecular events induced by RANK is NF- $\mathrm{kB}$ activation [16,17]. In non-stimulated cells, NF- $\mathrm{KB}$ proteins are found in the cytoplasm, but enter the nucleus upon cell stimulation. The NF- $\mathrm{KB}$ pathway is composed of two distinct pathways: the canonical and the alternative. Both are shown to be essential in osteoclastogenesis [17-20]. NF- $\mathrm{kB}$ transcription factor activity is the hallmark of inflammation. In this respect, the role of lycopene as an anti-inflammatory agent was studied. Joo et al. [21] demonstrated that tomato lycopene extract inhibits NF- $\mathrm{kB}$ signaling, leading to reduced-lipopolysaccharide-induced pro-inflammatory gene expression in rat small intestinal epithelial cells. A similar anti-inflammatory effect of lycopene was shown in lipopolysaccharide-induced peritoneal macrophages [22]. These findings were supported by a study showing that lycopene regulates cigarette smoke-driven inflammation by inhibition of macrophage NF-kB activity [23]. However, whether inhibition of NF-KB signaling is involved in lycopene's effect in osteoclasts is not yet known.

In several types of cell including bone osteoblasts, we have previously shown that carotenoid oxidation products, and not the intact carotenoid, stimulate the electrophile/antioxidant response element (ARE/Nrf2) transcription system [24] and inhibit the NF-kB transcription system [25]. Similar opposing effects on these two transcription systems were obtained with synthetic dialdehyde carotenoid derivatives (diapocarotene-dials), which can be formed by spontaneous oxidation [26] or after chemical [27] or enzymatic [28] catalyzed oxidation of various carotenoids. Although such diapocarotene-dials have not been identified in human or animal samples, mono-apocarotenals, that have similar, but lower activities [24], have been documented in raw tomatoes [29]. The synthetic diapocarotene-dials also inhibited estrogen signaling in breast cancer cells but did not inhibit and even stimulated it in osteoblast bone cells [30]. In addition, we demonstrated that the activity of individual diapocarotene-dials in inducing the ARE/Nrf2 transcription system and inhibiting the NF- $\mathrm{KB}$ transcription system depends on the reactivity of the conjugated double bond in reactions such as Michael addition. This reactivity is determined by the electron density around the reactive carbon atoms (the fourth atom from each side of the molecule; see Table 1) [25]. We hypothesized that oxidized derivatives of lycopene and other carotenoids also act as the active mediators in inhibiting osteoclast differentiation. 
Table 1. Structures, Mulliken population values, and HOMO-LUMO energy gap of the synthetic derivatives.

\begin{tabular}{|c|c|c|c|c|}
\hline \multirow[t]{2}{*}{ Derivative $^{1}$} & \multirow[t]{2}{*}{ Structure } & \multicolumn{2}{|c|}{ Mulliken Population Values (Electron Density) } & \multirow{2}{*}{$\begin{array}{c}\text { HOMO-LUMO }{ }^{2} \text { Energy } \\
\text { Gap (kcal/mol) }\end{array}$} \\
\hline & & Left & Right & \\
\hline $6,14^{\prime}$ & & 6.16 & 6.10 & 189.51 \\
\hline $10,10^{\prime}$ & & 6.17 & 6.17 & 191.39 \\
\hline $8,8^{\prime}$ & & 6.21 & 6.21 & 178.21 \\
\hline $8,12^{\prime}$ & & 6.23 & 6.22 & 210.84 \\
\hline $12,12^{\prime}$ & & 6.24 & 6.24 & 214.61 \\
\hline
\end{tabular}

\footnotetext{
${ }^{1}$ The abbreviated names of the derivatives are derived from the putative position of oxidative cleavage in the carotenoid backbone, which could lead to the formation of these derivatives, Full names: 6,14'-diapocarotene-6,14'-dial $\left(6,14^{\prime}\right) ; 10,10^{\prime}$-diapocarotene-10,10'-dial $\left(10,10^{\prime}\right) ; 8,8^{\prime}$-diapocarotene-8, $8^{\prime}$-dial $\left(8,8^{\prime}\right)$; 8,12'-diapocarotene-8,12' -dial (8,12'); 12,12'-diapocarotene-12,12'-dial $\left(12,12^{\prime}\right) .{ }^{2}$ HOMO: High Occupied Molecular Orbitals; LUMO: Low Unoccupied Molecular Orbitals.
}

The aim of the current work was to determine if intact lycopene or its oxidized derivatives inhibit RANKL-induced osteoclast differentiation in RAW264.7 osteoclast progenitor cells. In addition, we determined the relative inhibition of osteoclast differentiation by various diapocarotene-dials in order to evaluate if the structure-activity relationship is similar to that of NF- $\mathrm{kB}$ inhibition [25]. After establishing this similarity, we aimed to verify if oxidized lycopene and the carotenoid derivatives interfere in the NF- $\mathrm{kB}$ pathway.

It is well accepted that the health benefits of a fruit and vegetable-based diet reside, at least in part, in additive or synergistic activities of their phytonutrients. We hypothesized that this is true also for the inhibition of osteoclast differentiation; thus, another aim of this study was to look for synergy between carotenoid derivatives and other phytonutrients. To check this possibility, we compared the inhibition of osteoclastogenesis by a carotenoid derivative alone to its combination with phytochemicals belonging to the large family of polyphenols, several of which are known to have beneficial effects on bone health. Polyphenols are present in many foods of plant origin and are characterized by having one or several phenolic groups in their chemical structure. There are over 500 different polyphenols in foods, and the mean intake of all of them is about $1 \mathrm{~g}$ per day, which is split between many specific polyphenols [31]. From the various polyphenols, we selected two which affect osteoclasts—curcumin [32,33] and carnosic acid [34,35]—and studied their cooperativity with carotenoid derivatives in inhibiting osteoclast activity.

\section{Materials and Methods}

\subsection{Materials}

Crystalline lycopene preparations, purified from tomato extract ( $>97 \%)$, were supplied by Lycored Ltd. (Beer Sheva, Israel). Tetrahydrofuran (THF), containing $0.025 \%$ butylated hydroxytoluene (BHT) as an antioxidant, was purchased from Aldrich (Milwaukee, WI, USA). fetal calf serum (FCS), sodium pyruvate, and $\mathrm{Ca}^{2+} / \mathrm{Mg}^{2+}$-free PBS were purchased from Biological Industries (Beth Haemek, Israel). DMEM medium was purchased from Gibco (Grand Island, NY, USA). $\alpha$-MEM medium, Dimethyl sulfoxide (DMSO), P-nitrophenyl phosphate and acid phosphatase leukocyte kit (387A) were purchased from Sigma Chemicals. Curcumin was purchased from Cayman Chemicals (Ann Arbor, MI, USA). Carnosic acid was purchased from Alexis Biochemicals (Läufenfingen, Switzerland). 


\subsection{Ethanolic Extract of Lycopene}

An ethanolic extract was prepared from a crystalline lycopene preparation that was stored at $-20^{\circ} \mathrm{C}$ for about a year. $27.2 \mathrm{mg}$ of this partially oxidized lycopene were extracted with ethanol and then evaporated under a vacuum, yielding $24 \mathrm{mg}$ ( $\sim 88 \%$ of the original lycopene). The extract was dissolved in $1.8 \mathrm{~mL}$ ethanol, and the resulting solution contained no detectable lycopene, as verified by measuring the absorption spectrum at 250-600 nm (not shown). The lycopene crystals that remained after the ethanol extraction $(3.2 \mathrm{mg}$ ) were defined as intact lycopene based on the characteristic absorption spectrum (Figure 1b).

(a)

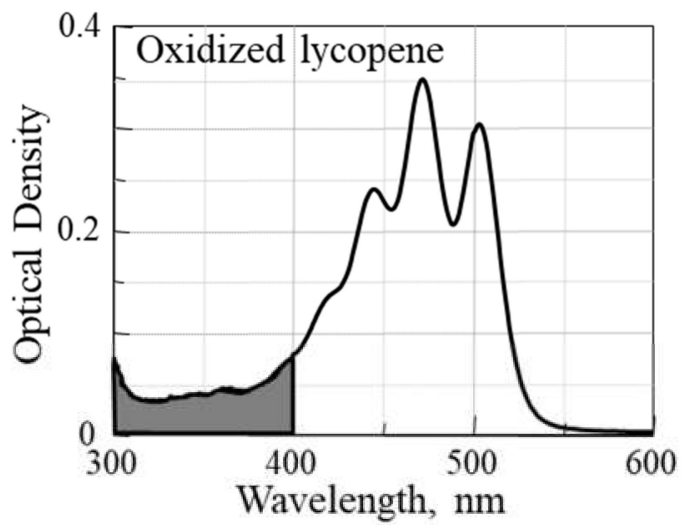

(b)

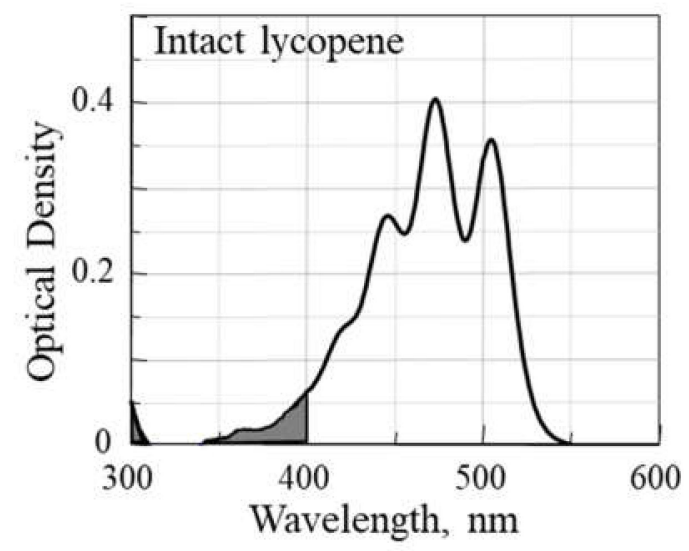

(c)
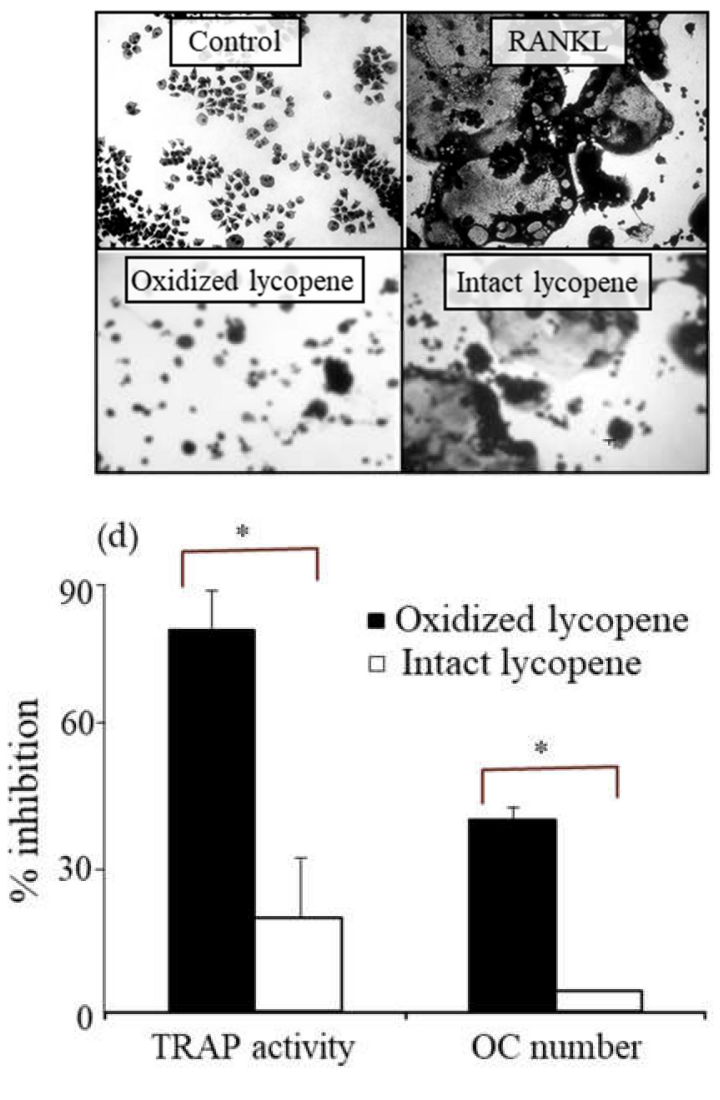

Figure 1. Oxidized lycopene inhibits osteoclast differentiation. Characteristic absorption spectrum of the oxidized lycopene (a) and intact lycopene (b) used in the experiment. (c,d) RAW264.7 cells $\left(4 \times 10^{4}\right.$ cells/well) were incubated either alone or in the presence of RANKL $(20 \mathrm{ng} / \mathrm{mL})$ without lycopene or with one of its two types at a concentration of $10 \mu \mathrm{M}$. (c) Photographs of cells after staining for tartrate resistant acid phosphatase- (TRAP)-positive cells (original magnification $\times 100$ ). (d) Counting of multinucleated TRAP-positive cells and measurement of TRAP activity. Values are the means \pm SD of three experiments, each performed in triplicate. ${ }^{*} p<0.01$ for the difference between the $\%$ inhibition with oxidized lycopene vs. intact lycopene.

\subsection{Synthetic Carotenoid Derivatives}

Synthetic carotenoid derivatives, shown in Table 1 ( $>99 \%$ purity), were synthesized and provided by BASF (Dr. Hansgeorg Ernst, Ludwigshafen, Germany). The compounds, characterized using UV/VIS spectroscopy, HPLC, and 1H and 13C NMR, proved to be in an all-E-configuration. 


\subsection{Energy Calculations}

The electronic structure method Restricted Hartree-Fock (RHF) was applied to resolve the chemical optimized structures [36] using the GAMESS suite of programs [37]. The basis set DZV was used to model all molecular orbitals. Atomic charges were computed using the Mulliken scheme, in which the atomic orbitals and molecular orbital coefficients were converted to an orthogonal set. These calculations provide electron populations that are less sensitive to basis set type [38]. In each molecule, there are two reactive carbon atoms in the conjugated chain. The Mulliken analysis was achieved for the two reactive carbon atoms (fourth position from both sides of the molecule, Table 1).

\subsection{Solubilization of the Test Compounds}

The synthetic derivatives were dissolved at $2 \mathrm{mM}$ in THF and stored at $-20^{\circ} \mathrm{C}$. Before experiments, the absorption spectra of the compounds were checked for stability. Spectrophotometric analysis was performed at 250-600 nm using the V 530 UV/VIS spectrophotometer (Jasco, Easton, MD, USA). The THF stock solutions of each derivative were diluted in chloroform, and the concentrations were calculated according to the absorption values at the characteristic peaks [24]. The concentration of carotenoid solutions in the THF were calculated from the absorption after dilution in n-hexane: dichlomethane (5:1) containing $1.2 \mathrm{mM}$ BHT.

Stock solutions were added to the cell culture medium under vigorous stirring and nitrogen flow to prevent oxidation. The final concentration of the carotenoids in the medium was measured by spectrophotometry after extraction in 2-propanol and n-hexane-dichloromethane. Stock solutions of curcumin $(10 \mathrm{mM})$ were prepared in DMSO. Carnosic acid $(30 \mathrm{mM})$ was dissolved in absolute ethanol. All procedures were done under reduced lighting, and the final concentrations of THF, ethanol, and DMSO in the medium were $0.75 \%, 0.15 \%$, and $0.2 \%$, respectively. The vehicles had no effect on the measured parameters.

\subsection{Cell Culture}

RAW264.7, murine monocyte-macrophage-like cells purchased from American Type Culture Collection (Manassas, VA, USA), were kindly provided by Dr. Bennie Gaiger (Weizmann Institute of Science, Rehovot, Israel). Cells were grown in DMEM (Gibco) with penicillin (500 units $/ \mathrm{mL}$ ), streptomycin $(0.5 \mathrm{mg} / \mathrm{mL})$, and $10 \%$ FCS. In all experiments, the cells were grown in $\alpha$-MEM medium containing the same supplements, as well as RANKL (R\&D systems, Minneapolis, MN, USA). Cells were grown in a humidified atmosphere of $95 \%$ air and $5 \% \mathrm{CO}_{2}$, at $37^{\circ} \mathrm{C}$.

\subsection{Differentiation Assays}

Cells were seeded in 96-well plates (40,000 cells/mL), and test compounds were added 7-16 h later. In order to evaluate osteoclast differentiation, both TRAP activity and the number of TRAP-positive multinucleated cells were examined. TRAP activity in the cells was determined after 2-3 days by fixation with formaldehyde for $5 \mathrm{~min}(3.7 \% v / v)$ and washing with ethanol $(95 \% v / v)$ for one $\min$, followed by incubating the cells with 10-20 mM p-nitrophenyl phosphate (Sigma-Aldrich, St. Louis, $\mathrm{MO}, \mathrm{USA}$ ) in the presence of $10 \mathrm{mM}$ sodium tartrate. The reaction was stopped with $0.1 \mathrm{M} \mathrm{NaOH}$, and absorbance was measured at $410 \mathrm{~nm}$. TRAP levels were corrected to cell number using crystal violet. Briefly, after fixation, cells were incubated for $15 \mathrm{~min}$ with crystal violet $(0.5 \%)$ and washed thoroughly in tap water. After drying overnight, the dye was dissolved in sodium citrate, and absorbance was measured at $550 \mathrm{~nm}$. It should be noted that the values of crystal violet staining, after treatment of cells with the various dietary compounds, did not differ by more than $20 \%$ from the value measured with RANKL alone. After 4 days, cells were fixed and stained for TRAP using a Leukocyte Acid Phosphatase kit (Sigma-Aldrich, St. Louis, MO, USA). The number of TRAP-positive multinucleated ( $>5$ nucleus) cells was counted under a light microscope. 


\subsection{Cell Fractionation}

Cells were seeded in $100-\mathrm{mm}$ plates $\left(3 \times 10^{6}\right.$ cells per plate). $16 \mathrm{~h}$ later, the test compounds were added for $3 \mathrm{~h}$ of pre-incubation. Then RANKL was added for $40 \mathrm{~min}$. Cells were lysed with ice-cold cytosolic lysis buffer containing $10 \mathrm{mM} \mathrm{NaCl}, 10 \mathrm{mM}$ Tris $\mathrm{HCl}$ (pH 7.4), $0.1 \mathrm{mM} \mathrm{NP}-40,3 \mathrm{mM}$ $\mathrm{MgCl}_{2}, 1 \mathrm{mM}$ EDTA, $2 \mathrm{mM}$ sodium orthovanadate, $50 \mathrm{mM} \mathrm{NaF}, 0.2 \mathrm{mM}$ DTT, and 1:25 Complete ${ }^{\mathrm{TM}}$ protease-inhibitor cocktail, and centrifuged at $310 \times g$ for $10 \mathrm{~min}$ at $4{ }^{\circ} \mathrm{C}$. Supernatant samples were then centrifuged at $20,000 \times g$ for $10 \mathrm{~min}$ at $4{ }^{\circ} \mathrm{C}$ (cytosolic fraction). The pellet was resuspended with cytosolic lysis buffer and centrifuged $\left(310 \times g\right.$ for $10 \mathrm{~min}$ at $\left.4{ }^{\circ} \mathrm{C}\right)$ twice. The nucleus pellet was lysed with nuclear lysis buffer containing $20 \mathrm{mM}$ Hepes $\mathrm{KOH}(\mathrm{pH}=7.9), 1: 4$ glycerol, $420 \mathrm{mM} \mathrm{NaCl}$, $1.5 \mathrm{mM} \mathrm{MgCl} 2,0.2 \mathrm{mM}$ EDTA, $2 \mathrm{mM}$ sodium orthovanadate, $50 \mathrm{mM} \mathrm{NaF}, 0.2 \mathrm{mM}$ DTT, and 1:25 Complete ${ }^{\mathrm{TM}}$ protease-inhibitor cocktail, and incubated on ice for $20 \mathrm{~min}$. The samples were centrifuged at 20,000 $\times \mathrm{g}$ for $10 \mathrm{~min}$ at $4{ }^{\circ} \mathrm{C}$ (nuclear fraction). Both fractions were further treated as described for Western blotting using the following antibodies: rabbit polyclonal IgG anti-p65 (\#3034) (Cell Signaling Technology, Danvers, MA, USA), mouse monoclonal IgG anti-NF-kB p52 (sc-7386), goat polyclonal IgG anti-lamin B (sc-6216), rabbit polyclonal anti-b-tubulin (sc-9104) (Santa Cruz Biotechnology, Santa Cruz, CA, USA), and peroxidase-conjugated donkey anti-rabbit IgG (711-035-152) (Jackson Immunoresearch Laboratories, Inc. West Grove, PA, USA.).

\subsection{Western Blotting}

RAW264.7 cells were seeded in 100-mm plates $\left(3 \times 10^{6}\right.$ cells per plate). $16 \mathrm{~h}$ later, the test compounds were added for $3 \mathrm{~h}$ of pre-incubation. Then RANKL was added for $15 \mathrm{~min}$. Next, whole cell extracts were prepared. Briefly, cells were lysed in ice-cold lysis buffer containing $50 \mathrm{mM}$, HEPES (pH 7.5), $150 \mathrm{mM} \mathrm{NaCl}, 10 \%(v / v)$ glycerol, 1\% (v/v) Triton X-100, $1.5 \mathrm{mM}$ EGTA, $2 \mathrm{mM}$ sodium orthovanadate, $20 \mathrm{mM}$ sodium pyrophosphate, $50 \mathrm{mM} \mathrm{NaF}, 1 \mathrm{mM}$ DTT, and 1:25 Complete ${ }^{\mathrm{TM}}$ protease-inhibitor cocktail (Roche Molecular Biochemicals, Mannheim, Germany), and centrifuged at $20,000 \times \mathrm{g}$ for $10 \mathrm{~min}$ at $4{ }^{\circ} \mathrm{C} .50 \mu \mathrm{g}$ protein of the supernatants were separated by SDS-PAGE, and then blotted into nitrocellulose membrane (Whatman, Dassel, Germany). The membranes were blocked with $5 \%$ milk for $2 \mathrm{~h}$ and incubated with primary antibodies overnight at $4{ }^{\circ} \mathrm{C}$, followed by incubation with peroxidase-conjugated secondary antibodies (Promega, Madison, WI, USA) for $2 \mathrm{~h}$. The protein bands were visualized using Western Lightning ${ }^{\mathrm{TM}}$ Chemiluminescence Reagent Plus (PerkinElmer Life Sciences, Inc., Boston, MA, USA). The blots were stripped and re-probed for the constitutively present protein calreticulin, which served as the loading control. The optical density (OD) of each band was quantitated using ImageQuant TL7.0 (GE Healthcare, Chicago, IL, USA). The following antibodies were used: mouse monoclonal IgG anti-phospho-IкB $\alpha$ Ser32/36 (\#9246) (cell signaling technology), mouse monoclonal IgG anti-IkB (OP142) (Oncogene Research Products, La Jolla, CA, USA), and rabbit polyclonal IgG anti-calreticulin (PA3-900) from Affinity BioReagent (Golden, CO, USA).

\subsection{Statistical Analysis}

All experiments were repeated at least three times. The significance of the differences between the means of the various subgroups was assessed by a two-tailed Student's $t$ test using Microsoft Excel. Statistically significant differences among the multiple groups were analyzed by a one-way ANOVA, followed by a Newman-Keuls multiple comparison test using the GraphPad Prizm 5.0 program (GraphPad Software, San Diego, CA, USA). $p<0.05$ was considered statistically significant. The interaction between the polyphenols and the carotenoid derivatives in inhibiting TRAP activity was assessed by $\mathrm{CI}$ analysis using Calcusyn version 2.1, (BIOSOFT, Cambridge, Great Britain). The CI values were calculated based on the $\%$ inhibition by each agent individually and by the combinations at a constant ratio. 


\section{Results}

\subsection{Oxidized Lycopene Is More Potent than Intact Lycopene in Inhibiting RANKL-Induced} Osteoclast Differentiation

Using a partially oxidized lycopene, we separated the hydrophobic intact lycopene, which is not soluble in ethanol, from its more hydrophilic oxidation products by ethanol extraction. The hydrophilic fraction comprised about $89 \%$ by weight of the oxidized lycopene preparation. The spectral absorption of the non-extracted oxidized lycopene preparation (Figure 1a) showed higher absorption in the 300-400 $\mathrm{nm}$ range than that of the intact lycopene preparation (Figure $1 \mathrm{~b}$ ), suggesting that the latter does not contain a considerable amount of oxidized derivatives. We examined the effect of these intact and oxidized preparations of lycopene in the inhibition of RANKL-induced osteoclast differentiation in RAW264.7 cells. The picture in Figure 1c shows small monocytes in the control and large multinucleated osteoclasts in the RANKL-treated cells. Similar osteoclasts are seen in cells treated with RANKL and intact lycopene, in contrast to cells treated with RANKL and oxidized lycopene that showed no multinucleated osteoclasts, suggesting that the oxidized lycopene inhibited osteoclast differentiation. A quantitative analysis showed that the oxidized lycopene preparation was much more potent in inhibiting TRAP activity and formation of TRAP+ multinucleated osteoclasts than the intact lycopene (Figure 1d). To evaluate whether the treatment of cells with oxidized or intact lycopene affect cell survival, the values of cell protein, measured by crystal violet staining (used to normalize TRAP results), was compared to that of cells treated with RANKL alone. The average of four experiments, each performed in triplicate was 46,700 $\pm 2000,44,600 \pm 4300$, and 49,100 \pm 5400 for RANKL alone, RANKL with oxidized lycopene, and RANKL with intact lycopene, respectively. Thus, the results presented in Figure $1 \mathrm{~d}$ represent inhibition of osteoclast differentiation and are not attributed to cell death.

\subsection{Diapocarotene-Dials Inhibition of RANKL-Induced Osteoclast Differentiation Depends on the Electron Density around the Reactive Carbon Atoms of the Molecules}

To determine the effect of diapocarotene-dials on RANKL-induced osteoclast differentiation in RAW264.7 cells, we incubated these cells with RANKL and with different concentrations of 6,14'-diapocarotene-6,14'-dial $\left(6,14^{\prime}\right)$, and assessed TRAP activity and the formation of multinucleated TRAP+ cells. The percent inhibition by $6,14^{\prime}$ was similar for the two measured parameters. The inhibition of osteoclast differentiation by this derivative was dose dependent, and almost complete inhibition was observed at $10 \mu \mathrm{M}$ (Figure 2a). We measured TRAP activity and the formation of multinucleated TRAP+ cells with $10 \mu \mathrm{M}$ of two different diapocarotene-dials $\left(6,14^{\prime}\right.$ and $\left.10,10^{\prime}\right)$. The percent inhibition by each compound was similar for the two measured parameters, and 6,14' was more active than 10,10' (Figure 2b). Treatment of cells with diapocarotene-dials alone without RANKL did not result in any response (data not shown). Different diapocarotene-dials inhibited osteoclast differentiation to different extents (Figure 2c). In previous work, we have shown that the activity of individual carotenoid derivatives in inhibiting the NF- $\mathrm{B}$ reporter gene activity [25] depends on the electron density around the reactive carbon atoms (the fourth atom from each side of the molecule). Since NF-KB is known to partially mediate RANKL signaling, we assumed that RANKL-induced osteoclast differentiation would similarly depend on the structure of the diapocarotene-dials. Indeed, a strong correlation $\left(R^{2}=0.938\right)$ exists between the electron density at the reactive $C$-atom of the various diapocarotene-dials (Table 1 ) and the \% inhibition of TRAP activity (Figure $2 \mathrm{c}$ ). The results strengthen the evidence that the potency of these derivatives depends on the electron density around the reactive carbon atoms. 
(a)

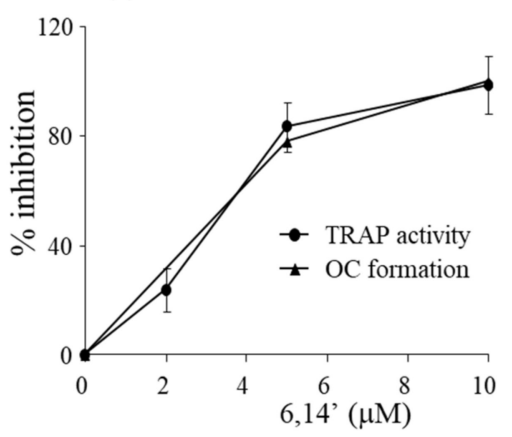

(b)

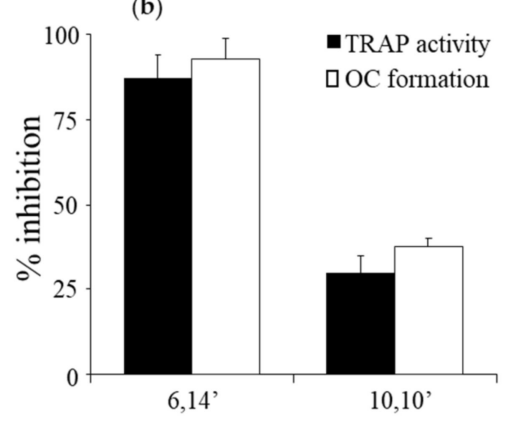

(c)

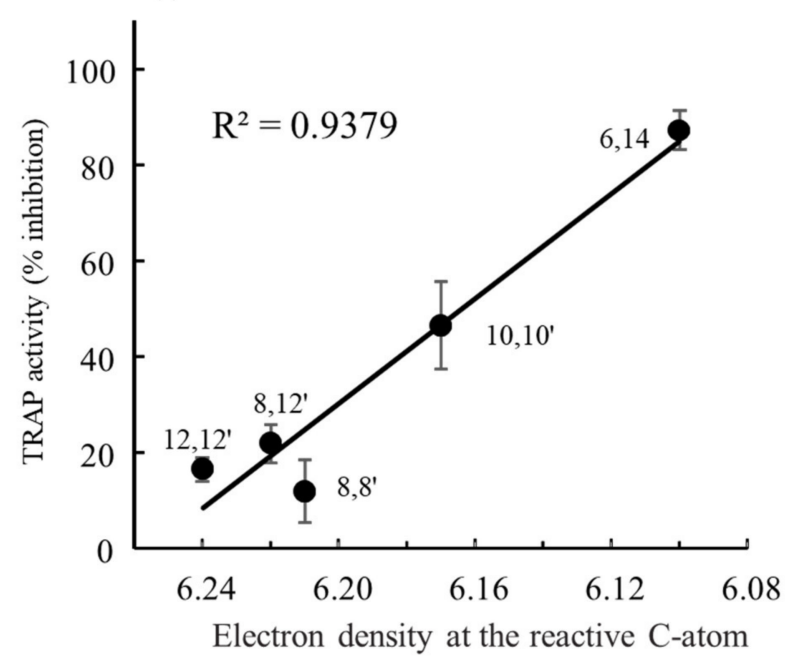

Figure 2. Diapocarotene-dials inhibit RANKL-induced osteoclastogenesis. Osteoclast differentiation was measured as described in the Materials and Methods section and in Figure 1. Cell were incubated with RANKL alone or with (a) different concentrations of the diapocarotene-dial $6,14^{\prime}$ or $(\mathbf{b}, \mathbf{c})$ with $10 \mu \mathrm{M}$ different diapocarete-dials. Inhibition is shown in relation to positive control with RANKL. (b) Comparison of the inhibition by $6,14^{\prime}$ and $10,10^{\prime}$. Values are the means \pm SE of $3-14$ experiments, each performed in triplicate, $p<0.01$ for the difference between the $\%$ inhibition with $6,14^{\prime}$ vs. $10,10^{\prime}$. (c) Correlation between the electron density at the reactive $\mathrm{C}$-atom of the various diapocarotene-dials and the \% inhibition of osteoclast TRAP activity. Values are the means \pm SE of 3-11 independent experiments, each performed in triplicate. The results are statistically significant (ANOVA test) $p<0.05$.

\subsection{Diapocarotene-Dials Inhibit RANKL-Induced NF- $\kappa B$ Activation in Osteoclast Precursors}

Activation of NF- $\mathrm{BB}$ is comprised of two pathways: the canonical and the alternative or non-canonical. Phosphorylation and degradation of its inhibitory subunit $\mathrm{I} \kappa \mathrm{B} \alpha$ is an essential step in activating the canonical pathway. Western blot analysis revealed that the active diapocarotene-dials $6,14^{\prime}$ and 10,10' significantly inhibit RANKL-induced IKB $\alpha$ phosphorylation and degradation, as opposed to the inactive diapocarotene-dial 8,8' and 12,12' (Figure 3a,b), in accordance with the structure-activity relationship described above. It is noticeable in Figure $3 a$ that the level of pIkB in the 6,14' -treated sample was greater than with RANKL alone; however, quantitating the pIkB:IkB ratio (Figure 3b, corrected to calreticulin) clearly shows that $6,14^{\prime}$ treatment reduced this ratio by more than $30 \%$, which indicates downregulation of I $\mathrm{K} \mathrm{B} \alpha$ phosphorylation and inhibition of RANKL-induced degradation of $I_{\kappa} B \alpha$. I $\mathrm{K} B \alpha$ degradation enables the translocation of p 65 to the nucleus. Fractionation analysis of nuclear p65 (Figure 3c,d) shows some reduction in the nucleus after treatment with lycopene or its active derivatives; however, this reduction was not statistically significant, but may suggest that the active derivatives attenuate the canonical pathway of NF- $\mathrm{kB}$. 
(a)

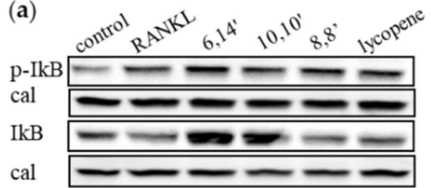

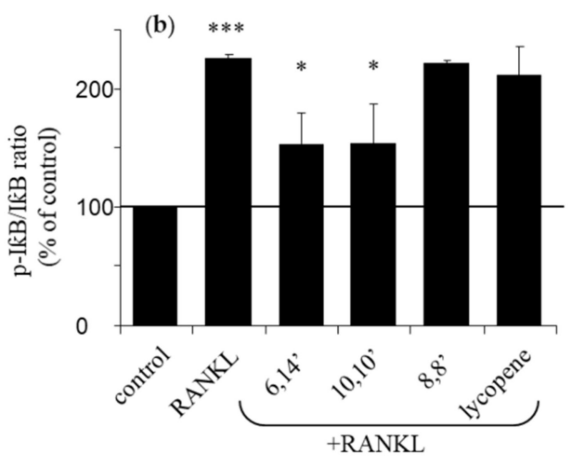
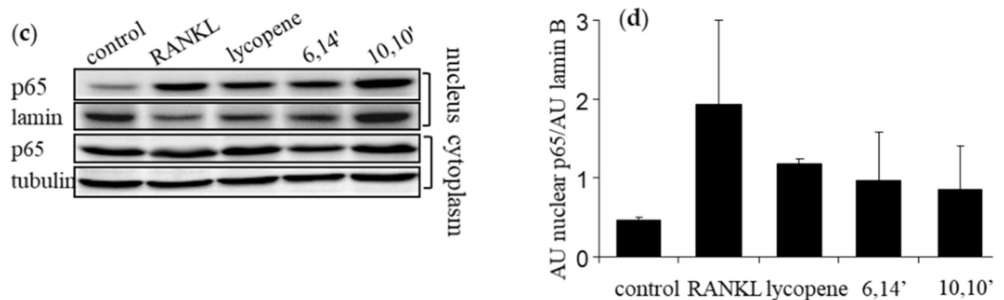

control RANKL lycopene 6,14, 10,10,
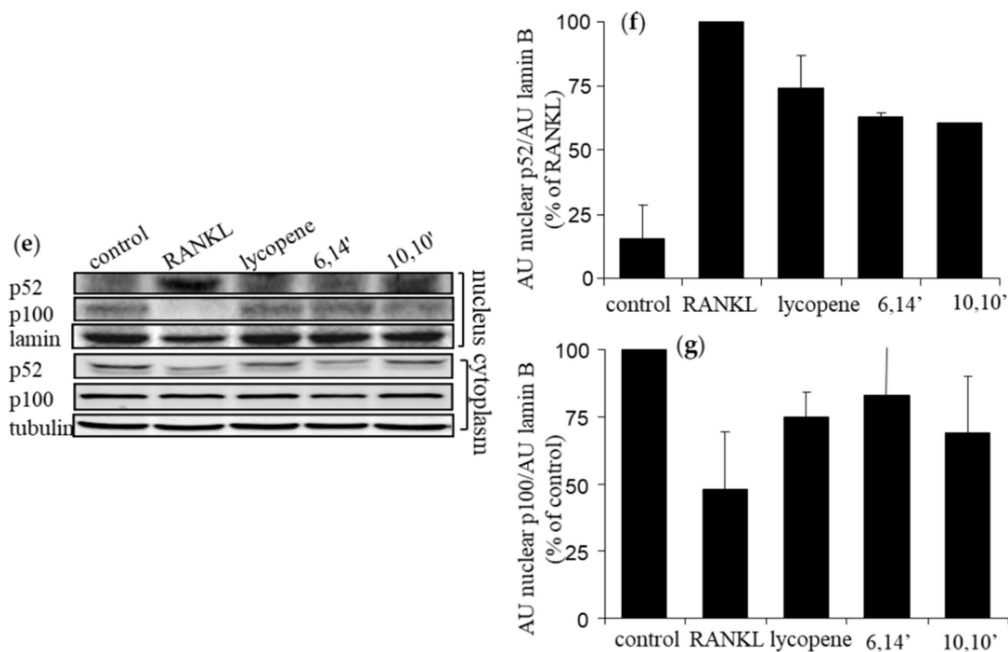

Figure 3. Diapocarotene-dials attenuate the NF-кB signal in RANKL-activated RAW264.7 cells. $5 \times 10^{6}$ cells in 100-mm plates were either incubated alone or in the presence of the indicated diapocarotene-dials $(10 \mu \mathrm{M})$ or lycopene $(10 \mu \mathrm{M})$ for $2 \mathrm{~h}$, and then treated with RANKL $(40 \mathrm{ng} / \mathrm{mL})$ for $15 \mathrm{~min}(\mathbf{a}, \mathbf{b})$ and $40 \mathrm{~min}(\mathbf{c}-\mathbf{g})$. Whole cell lysates $(\mathbf{a}, \mathbf{b})$ and cytoplasmatic and nuclear fractions (c-g) were prepared and analyzed by Western blotting, as described in Materials and Methods. Values are the means

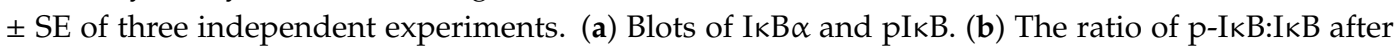
normalization with calreticulin (cal) is presented as the $\%$ of the control without RANKL. ${ }^{* * *} p<0.001$ for the difference between RANKL to the control. ${ }^{*} p<0.05$ for the difference between RANKL to $6,14^{\prime}$ and 10,10'. (c) Blots of nuclear and cytosolic p65. (d) Nuclear p65 levels normalized to laminin B. (e) Blots of nuclear and cytosolic p52 and p100. (f) Nuclear p52 levels normalized to laminin B. Results are \% of RANKL. (g) Nuclear p100 levels normalized to laminin B. Results are \% of control.

Degradation of the precursor p100 to the active NF- $\mathrm{BB}$ component $\mathrm{p} 52$ is essential in activating the alternative pathway. RANKL reduced the nuclear level of p100 and increased that of p52 (Figure 3e-g). Treatment with lycopene, 6,14' and 10,10' suggests inhibition of the RANKL-induced conversion of p100 to p52, but the changes were not significant. In addition, these compounds preserved the cytosolic levels of p52 and prevented its translocation to the nucleus (Figure 3e). These results may suggest that active diapocarotene-dials inhibit both pathways in RANKL-induced NF- $\mathrm{kB}$ activation in RAW264.7 cells. 
3.4. Active Diapocarotene-Dials Inhibit RANKL-Induced TRAP Activity Synergistically with Curcumin and with Carnosic Acid

RAW264.7 cells were incubated with combinations of the diapocarotene-dial 6,14', with the polyphenols curcumin and carnosic acid. At low concentrations of each agent, these combinations produced a synergistic anti-differentiative effect in RANKL-induced cells. Synergistic effects were evaluated using Calcusyn Software for Dose Effect Analysis. Dose effect curves and CI values for the combination of 6,14' with curcumin (Figure $4 a, b$ ) and 6,14' with carnosic acid (Figure $4 c, d$ ) are presented. Most CI values are below 1.0, indicating some synergy at most of the tested concentrations. However, CI values at low concentrations, resulting in $20-40 \%$ inhibition, are smaller than 0.5 , indicating a strong synergistic effect at concentrations that can be found in human blood.

(a)

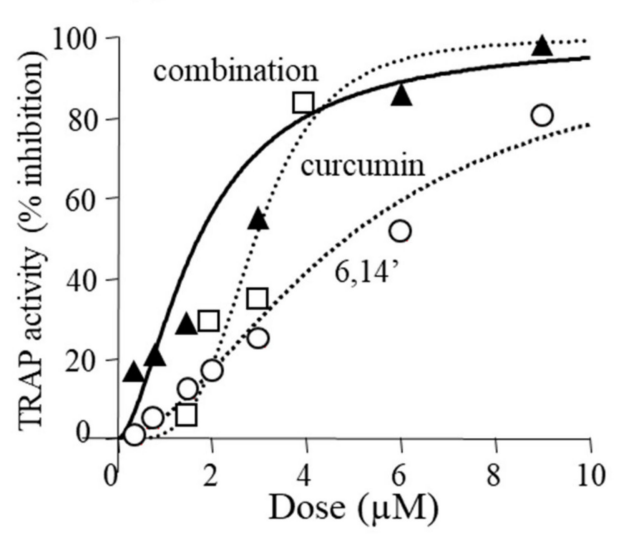

(b)

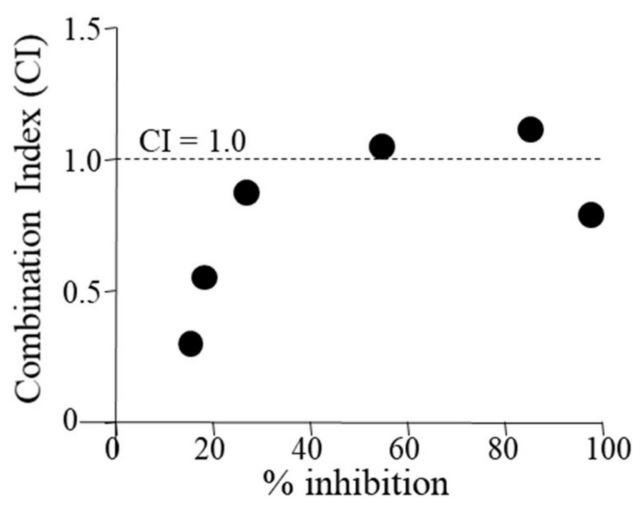

(c)

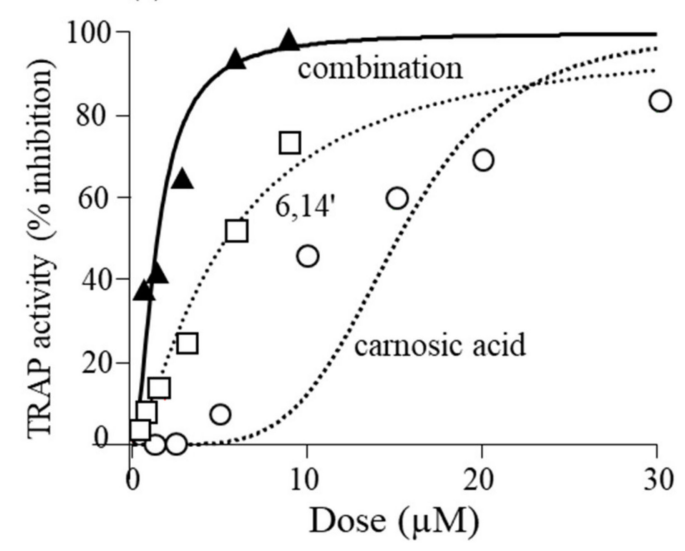

(d)

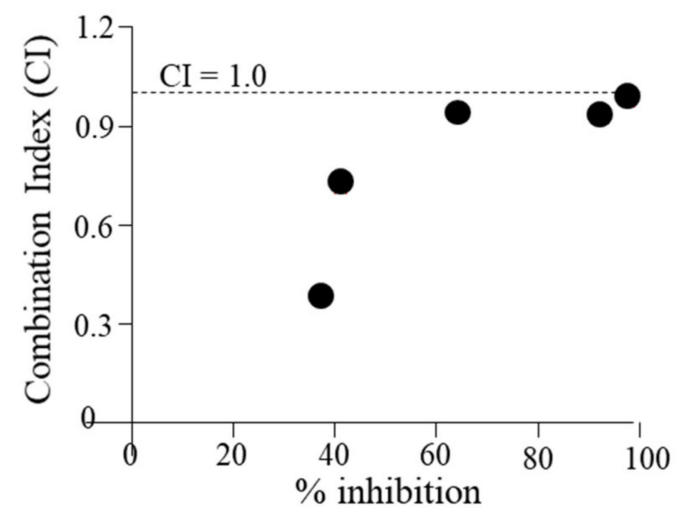

Figure 4. Synergistic effect of $6,14^{\prime}$ with curcumin or carnosic acid. Osteoclast differentiation was measured as described in the Materials and Methods section and in Figure 1. Cell were incubated with RANKL alone or in the presence of different concentrations of $6,14^{\prime}$ with curcumin or with carnosic acid at constant concentration ratios. Values are the means of 3-4 experiments, each performed in triplicate. (a) The dose effect curve of the combinations of $6,14^{\prime}$ with curcumin at a ratio of 1:1. (b) Combination index (CI) values for the combinations of 6,14' with curcumin. (c) The dose effect curve of the combinations of 6,14' with carnosic acid at a ratio of 1:3. (d) CI values for the combinations of $6,14^{\prime}$ with carnosic acid.

\section{Discussion}

The main finding of the current study is that the inhibition of RANKL-induced osteoclast differentiation by partially oxidized lycopene is mediated by the hydrophilic oxidation products, and not by the intact lycopene molecule. Two different approaches led us to this conclusion. (a) We 
separated the spontaneously oxidized derivatives from the intact carotenoid using an ethanolic extraction of a partially oxidized lycopene preparation, and found that the oxidized lycopene inhibited osteoclast differentiation, whereas the parent molecule was nearly ineffective. (b) Using a series of fully characterized synthetic diapocarotene-dials, we found that these compounds inhibited osteoclast differentiation, and the inhibition efficiency correlated with the reactivity of the $\alpha, \beta$-unsaturated carbonyl groups in reactions such as Michael addition. This reactivity was estimated by calculating the electron density around the reactive carbon atoms, as shown in Table 1. The relative effectiveness of the diapocarotene-dials in the inhibition of osteoclastogenesis was similar to that found for activation of the ARE/Nrf2 transcription system [24] and for inhibition of TNF $\alpha$-induced NFkB activity [25] by carotenoid derivatives. Thus, it is suggested that the inhibition of RANKL-induced osteoclast differentiation resulted, at least partially, from inhibition of the RANKL-activated NF- $\mathrm{B}$ activity. In support of this suggestion, we found that the effective diapocarotene-dials reduced activation of the canonical NFKB pathway by RANKL. This was evident from the reduction of IKB $\alpha$ phosphorylation and degradation, and of $\mathrm{p} 65$ nuclear translocation that are essential stages in the canonical pathway. The active diapocarotene-dials and lycopene also reduced the nuclear translocation of p52, suggesting inhibition of the non-canonical NFKB pathway that is known to be involved in RANKL-induced osteoclast differentiation $[17,20]$.

Several proteins that take part in the NFkB pathway (e.g., I $\mathrm{NB}$ kinase) and the NFkB subunits (e.g., p65) contain cysteine residues which regulate NFKB activity $[39,40]$. The interaction of electrophiles with these cysteine thiols leads to NFKB pathway inhibition [39]. Similarly, it was shown that sulforaphane, its analogs [41], and other electrophiles such as carnosic acid [42], interact with reactive cysteine thiols in the Keap1 protein, leading to activation of the ARE/Nrf2 transcription system. Hydrophobic carotenoids such as lycopene and beta carotene are devoid of electrophilic groups which can interact with these cysteines; however, we previously demonstrated that apo-carotenal derivatives interact directly with thiol groups of IкB kinase [25]. In addition, we previously suggested, although did not directly prove, that carotenoid-oxidized derivatives activate the Nrf2 transcription system by interaction with such reactive cysteines in the Keap1 protein [24]. Since NFKB is involved in RANKL activation of osteoclast differentiation, and reduction of RANKL-induced ROS generation through activation of ARE/Nrf2 was suggested to inhibit this differentiation [35], we propose that the interaction of carotenoid derivatives with thiol groups in proteins critically involved in NFKB and ARE/Nrf2 pathways may be part of the mechanism for the inhibition of osteoclast differentiation by oxidized derivatives of lycopene and other carotenoids.

As all the effects of carotenoid derivatives were obtained in in-vitro cellular systems, an important question is whether such effects can also be obtained in-vivo. Although this question is difficult to answer directly, what we can try to resolve is whether such apo-carotenals can be found in mammalian blood and tissues, and what their potential sources are. It is possible that the derivatives are consumed with the carotenoids from foods or formed inside the body. Diapocarotene-dials similar to those used in the current study were only rarely found in plants, most likely because they are reactive and instable molecules, which makes them difficult to detect in biological samples [43]. Recently, Jia et al. identified in Arabidopsis a presumed carotenoid-derived dialdehyde, anchorene, (12,12'-diapocaroten-12,12'-dial according to our nomenclature) that promotes the development of anchor roots [44]. However, such rare plant metabolites probably have no importance in the human diet and, thus, it is not surprising that diapocarotene-dials have not been detected in mammalian samples. In contrast, mono-apocarotenals, both, $\beta$-apo-carotenals [45] and lycopenals [46], were identified in both human and plant samples. Specifically, apolycopenals including apo-10'-, apo-12'-, apo-14'-, and apo-15'-lycopenal were found in foods that are rich in lycopene such as raw tomatoes, red grapefruit, and watermelon. These lycopenals were also detected in the plasma of individuals who had consumed tomato juice for 8 weeks [46]. Similar compounds, apo-8'- and apo-12'-lycopenals, were detected in rat livers [47], and in a recent study, additional apo-carotenals were detected, including $\beta$-apo-12'-carotenal and several apo-zeaxanthinals and apo-luteinals [48]. The concentration of these apo-lycopenals in 
foods is very low, and is about 500 times lower than that of lycopene [49], with similar relative concentrations found in human plasma. However, it is not clear if apo-carotenals are absorbed from foods or produced in the body since it was found that 4-week supplementation of high- $\beta$-carotene and high-lycopene tomato juice did not lead to detectable concentrations of most $\beta$-apocarotenals or lycopenals that were present in the juice [50]. It is not certain if the accessibility of these compounds to bone and other cells in-vivo is sufficient to achieve the beneficial effects. Another alternative is that the apo-carotenals are formed inside the cells from the intact carotenoids, close to the site of their activity. Carotenoids are cleaved in the cells by the central cleavage enzyme $15,15^{\prime}$ - $\beta$-carotene oxygenase 1 (BCO1) and by the eccentric cleavage enzyme $\beta, \beta$-carotene- $9^{\prime}, 10^{\prime}$-oxygenase 2 (BCO2). The latter enzyme exhibits broad substrate specificity and cleaves both carotenes, such as lycopene, and xanthophylls like lutein [51]. The cleavage at the 9,10 double bond results in the formation of apo-10'-carotenals and 10,10'-diapocarotenals [52]. The 10,10'-diapocaroten-10,10'-dial was formed in vitro by incubation of $\beta$-carotene, as well as other carotenoids, with a recombinant BCO2 [53], but they were not detected in mammalian samples perhaps because of their high reactivity in biological systems [24]. Although, in the current study, we analyzed the activity of only the diapocarotenal, the reactivity of the apo-10'-lycopenals in the activation of the ARE/Nrf2 transcription system was only 1.5-2.5 fold lower than that of the 10,10'-diapocaroten-10,10'-dial [24]. Thus, it is possible that formation inside the osteoclasts may result in high enough local concentrations to lead to the inhibition of osteoclast differentiation.

Similar to carotenoid derivatives, other phyto-nutrients are known to inhibit osteoclast differentiation. These include flavonoids such as quercetin [54], polyphenols such as curcumin [55], and resveratrol [56], sulforaphane [57], and other isothiocyanates [58]. Although these nutrients have different chemical structures, they, and the carotenoid derivatives, all have electrophilic groups in common that can interact with thiol groups of reactive proteins of the NFKB system $[39,40]$ or other signaling pathways involved in osteoclast differentiation. A significant inhibition of osteoclastogenesis by the two polyphenols and by the carotenoid derivatives tested in the current study occur at high concentrations $\left(6,14^{\prime}\right.$ and curcumin—above $2 \mu \mathrm{M}$; carnosic acid—above $\left.10 \mu \mathrm{M}\right)$. Since, usually, these concentrations cannot be achieved in-vivo, we tested if their combination would result in activity at concentrations that could be achieved. We found a strong synergy between the polyphenols and the carotenoid derivative, $6,14^{\prime}$, leading to significant inhibition at concentrations below $1 \mu \mathrm{M}$. However, understanding the mechanism of this synergy would require extensive research to explore whether it results from synergistic inhibition of NFKB at different elements of the pathways or from interference in other pathways leading to osteoclast differentiation. For example, curcumin has been shown to inhibit the differentiation of human monocytes to osteoclasts by reducing phosphorylation and activation of mitogen-activated protein kinase (MAPK) proteins, such as ERK, p38, and JNK, which leads to reduced expression of c-Fos and NFATc1 that are essential for differentiation of osteoclasts [59]. Similar reduction of the phosphorylation of ERK, p38, and JNK MAPKs by carnosic acid was evident in RANKL-induced RAW264.7 cells, followed by a decrease in expression of c-Fos and NFATc1 and inhibition of osteoclastogenesis [35]. Thus, inhibition of MAPKs by the polyphenols, curcumin and carnosic acid, can increase the inhibitory effect of carotenoid derivatives that reduce RANKL-induced NFKB activation. Thummuri, et al. have shown in RAW264.7 cells and in mouse bone marrow macrophages that activation of ARE/Nrf2 and reduction of RANKL-induced ROS generation is one of the mechanisms for carnosic acid inhibition of osteoclastogenesis [35]. This is another possible explanation for the synergy we presented between the polyphenols and the carotenoid derivatives, as we have recently shown a strong synergy in ARE/Nrf2 activation in human keratinocytes by combinations of lycopene or tomato extract with carnosic acid or curcumin [60].

\section{Conclusions}

The current paper suggests that the protective effect of lycopene and other carotenoids on bone health, as shown in population and animal studies, is at least partially related to the inhibition of 
osteoclast differentiation and activity. This inhibition is possibly associated with that of the NFKB transcriptional system. Although most previous studies were done with carotenoids in foods or with pure carotenoids, we suggest that the osteoclasts are actually affected by the apo-carotenal carotenoid derivatives and not by the intact molecules.

Author Contributions: Conceptualization, S.O.-B., K.L.-H., J.L. and Y.S.; Formal analysis, S.O.-B., M.K., Y.M., K.A. and Y.S.; Funding acquisition, J.L. and Y.S.; Investigation, S.O.-B. and M.K.; Methodology, S.O.-B., M.K., K.L.-H., J.L. and Y.S.; Project administration, J.L. and Y.S.; Supervision, J.L. and Y.S.; Visualization, S.O.-B., M.K., K.L.-H., J.L. and Y.S.; Writing—original draft, S.O.-B., Y.M., J.L. and Y.S.; Writing—review \& editing, J.L. and Y.S. All authors have read and agreed to the published version of the manuscript.

Funding: This research was funded by Lycored Ltd., Beer Sheva, Israel (to Y.S. and J.L.) (899646).

Acknowledgments: We thank Hansgeorg Ernst (BASF, Ludwigshafen, Germany) and the late, Catherine Caris-Veyrat (INRA, Avignon University, Avignon, France) for their help in designing the synthetic carotenoid derivatives, and Hansgeorg Ernst for preparing and donating the carotenoid derivatives. We thank Tanya Svedlov, Lycored Ltd., Beer Sheva, Israel for donating purified lycopene and for the extraction of lycopene, and Robin Miller for English editing.

Conflicts of Interest: J.L. and Y.S. are consultants for Lycored Ltd., Beer Sheva, Israel. K.L.-H. is currently employed by Lycored, but at the time of conducting the experiments was a Ph.D. student at the laboratory of JL and Y.S. J.L. and Y.S. received research funding from Lycored. All other authors declare no conflict of interest. Lycored is a supplier to the dietary supplement and functional food industries worldwide. Lycored Ltd. had no role in the design of the study; in the collection, analyses, or interpretation of data; in the writing of the manuscript, or in the decision to publish the results.

\section{References}

1. Tucker, K.L.; Hannan, M.T.; Chen, H.; Cupples, L.A.; Wilson, P.W.; Kiel, D.P. Potassium, magnesium, and fruit and vegetable intakes are associated with greater bone mineral density in elderly men and women. Am. J. Clin. Nutr. 1999, 69, 727-736. [CrossRef]

2. Muhlbauer, R.C.; Li, F. Effect of vegetables on bone metabolism. Nature 1999, 401, 343-344. [CrossRef] [PubMed]

3. New, S.A.; Robins, S.P.; Campbell, M.K.; Martin, J.C.; Garton, M.J.; Bolton-Smith, C.; Grubb, D.A.; Lee, S.J.; Reid, D.M. Dietary influences on bone mass and bone metabolism: Further evidence of a positive link between fruit and vegetable consumption and bone health? Am. J. Clin. Nutr. 2000, 71, 142-151. [CrossRef] [PubMed]

4. Arscott, S.A. Food sources of carotenoids. In Carotenoids and Human Health; Tanumihardjo, S.A., Ed.; Springer: New York, NY, USA, 2013; pp. 1-331. [CrossRef]

5. Khachik, F. Distribution and metabolism of dietary carotenoids in humans as a criterion for development of nutritional supplements. Pure Appl. Chem. 2006, 78, 1551-1557. [CrossRef]

6. Parker, R.S. Carotenoids in human blood and tissues. J. Nutr. 1989, 119, 101-104. [CrossRef]

7. El-Sohemy, A.; Baylin, A.; Kabagambe, E.; Ascherio, A.; Spiegelman, D.; Campos, H. Individual carotenoid concentrations in adipose tissue and plasma as biomarkers of dietary intake. Am. J. Clin. Nutr. 2002, 76, 172-179. [CrossRef]

8. Shi, J.; Le Maguer, M. Lycopene in tomatoes: Chemical and physical properties affected by food processing. Crit. Rev. Biotechnol. 2000, 20, 293-334. [CrossRef]

9. Boyle, W.J.; Simonet, W.S.; Lacey, D.L. Osteoclast differentiation and activation. Nature 2003, 423, 337-342. [CrossRef]

10. Shen, C.L.; Von Bergen, V.; Chyu, M.C.; Jenkins, M.R.; Mo, H.; Chen, C.H.; Kwun, I.S. Fruits and dietary phytochemicals in bone protection. Nutr. Res. 2012, 32, 897-910. [CrossRef]

11. Cheong, S.H.; Chang, K.J. The preventive effect of fermented milk supplement containing tomato (Lycopersion esculentum) and taurine on bone loss in ovariectomized rats. Adv. Exp. Med. Biol. 2009, 643, 333-340. [CrossRef]

12. Rao, L.G.; Krishnadev, N.; Banasikowska, K.; Rao, A.V. Lycopene I-Effect on osteoclasts: Lycopene inhibits basal and parathyroid hormone-stimulated osteoclast formation and mineral resorption mediated by reactive oxygen species in rat bone marrow cultures. J. Med. Food 2003, 6, 69-78. [CrossRef] [PubMed] 
13. Kim, L.; Rao, A.V.; Rao, L.G. Lycopene II-Effect on osteoblasts: The carotenoid lycopene stimulates cell proliferation and alkaline phosphatase activity of SaOS-2 cells. J. Med. Food 2003, 6, 79-86. [CrossRef] [PubMed]

14. Costa-Rodrigues, J.; Fernandes, M.H.; Pinho, O.; Monteiro, P.R.R. Modulation of human osteoclastogenesis and osteoblastogenesis by lycopene. J. Nutr. Biochem. 2018, 57, 26-34. [CrossRef] [PubMed]

15. Suda, T.; Takahashi, N.; Udagawa, N.; Jimi, E.; Gillespie, M.T.; Martin, T.J. Modulation of osteoclast differentiation and function by the new members of the tumor necrosis factor receptor and ligand families. Endocr. Rev. 1999, 20, 345-357. [CrossRef]

16. Yavropoulou, M.P.; Yovos, J.G. Osteoclastogenesis-Current knowledge and future perspectives. J. Musculoskelet. Neuronal Interact. 2008, 8, 204-216.

17. Boyce, B.F.; Xiu, Y.; Li, J.; Xing, L.; Yao, Z. NF-kB-mediated regulation of osteoclastogenesis. Endocrinol. Metab. 2015, 30, 35-44. [CrossRef]

18. Asagiri, M.; Takayanagi, H. The molecular understanding of osteoclast differentiation. Bone 2007, 40, 251-264. [CrossRef]

19. Franzoso, G.; Carlson, L.; Xing, L.; Poljak, L.; Shores, E.W.; Brown, K.D.; Leonardi, A.; Tran, T.; Boyce, B.F.; Siebenlist, U. Requirement for NF-кB in osteoclast and B-cell development. Genes Dev. 1997, 11, 3482-3496. [CrossRef]

20. Maruyama, T.; Fukushima, H.; Nakao, K.; Shin, M.; Yasuda, H.; Weih, F.; Doi, T.; Aoki, K.; Alles, N.; Ohya, K.; et al. Processing of the NF-kB2 precursor p100 to p52 is critical for RANKL-induced osteoclast differentiation. J. Bone Miner. Res. 2010, 25, 1058-1067.

21. Joo, Y.E.; Karrasch, T.; Muhlbauer, M.; Allard, B.; Narula, A.; Herfarth, H.H.; Jobin, C. Tomato lycopene extract prevents lipopolysaccharide-induced NF- $\kappa B$ signaling but worsens dextran sulfate sodium-induced colitis in NF-kBEGFP mice. PLoS ONE 2009, 4, e4562. [CrossRef]

22. Hadad, N.; Levy, R. The synergistic anti-inflammatory effects of lycopene, lutein, beta-carotene, and carnosic acid combinations via redox-based inhibition of NF-kB signaling. Free Radic. Biol. Med. 2012, 53, 1381-1391. [CrossRef] [PubMed]

23. Simone, R.E.; Russo, M.; Catalano, A.; Monego, G.; Froehlich, K.; Boehm, V.; Palozza, P. Lycopene inhibits NF-kB-mediated IL-8 expression and changes redox and PPARgamma signalling in cigarette smoke-stimulated macrophages. PLoS ONE 2011, 6, e19652. [CrossRef] [PubMed]

24. Linnewiel, K.; Ernst, H.; Caris-Veyrat, C.; Ben-Dor, A.; Kampf, A.; Salman, H.; Danilenko, M.; Levy, J.; Sharoni, Y. Structure activity relationship of carotenoid derivatives in activation of the electrophile/antioxidant response element transcription system. Free Radic. Biol. Med. 2009, 47, 659-667. [CrossRef] [PubMed]

25. Linnewiel-Hermoni, K.; Motro, Y.; Miller, Y.; Levy, J.; Sharoni, Y. Carotenoid derivatives inhibit nuclear factor КB activity in bone and cancer cells by targeting key thiol groups. Free Radic. Biol. Med. 2014, 75, 105-120. [CrossRef] [PubMed]

26. Nara, E.; Hayashi, H.; Kotake, M.; Miyashita, K.; Nagao, A. Acyclic carotenoids and their oxidation mixtures inhibit the growth of HL-60 human promyelocytic leukemia cells. Nutr. Cancer 2001, 39, 273-283. [CrossRef]

27. Caris-Veyrat, C.; Schmid, A.; Carail, M.; Bohm, V. Cleavage products of lycopene produced by in vitro oxidations: Characterization and mechanisms of formation. J. Agric. Food Chem. 2003, 51, 7318-7325. [CrossRef]

28. Giuliano, G.; Al-Babili, S.; Von Lintig, J. Carotenoid oxygenases: Cleave it or leave it. Trends Plant. Sci. 2003, 8, 145-149. [CrossRef]

29. Ben-Aziz, A.; Britton, G.; Goodwin, T.W. Carotene epoxides of Lycopersicon esculentum. Phytochemistry 1973, 12, 2759-2764. [CrossRef]

30. Veprik, A.; Khanin, M.; Linnewiel-Hermoni, K.; Danilenko, M.; Levy, J.; Sharoni, Y. Polyphenols, isothiocyanates, and carotenoid derivatives enhance estrogenic activity in bone cells but inhibit it in breast cancer cells. Am. J. Physiol. Endocrinol. Metab. 2012, 303, E815-E824. [CrossRef]

31. Pérez-Jiménez, J.; Neveu, V.; Vos, F.; Scalbert, A. Identification of the 100 richest dietary sources of polyphenols: An application of the Phenol-Explorer database. Eur. J. Clin. Nutr. 2010, 64, S112-S120. [CrossRef]

32. Cao, F.; Liu, T.; Xu, Y.; Xu, D.; Feng, S. Curcumin inhibits cell proliferation and promotes apoptosis in human osteoclastoma cell through MMP-9, NF-KB and JNK signaling pathways. Int. J. Clin. Exp. Pathol. 2015, 8, 6037-6045. [PubMed] 
33. Cheng, T.; Zhao, Y.; Li, B.; Cheng, M.; Wang, J.; Zhang, X. Curcumin attenuation of wear particle-induced osteolysis via RANKL signaling pathway suppression in mouse calvarial model. Mediat. Inflamm. 2017, 2017, 5784374. [CrossRef] [PubMed]

34. Liu, M.; Zhou, X.; Zhou, L.; Liu, Z.; Yuan, J.; Cheng, J.; Zhao, J.; Wu, L.; Li, H.; Qiu, H.; et al. Carnosic acid inhibits inflammation response and joint destruction on osteoclasts, fibroblast-like synoviocytes, and collagen-induced arthritis rats. J. Cell. Physiol. 2018, 233, 6291-6303. [CrossRef] [PubMed]

35. Thummuri, D.; Naidu, V.G.M.; Chaudhari, P. Carnosic acid attenuates RANKL-induced oxidative stress and osteoclastogenesis via induction of Nrf2 and suppression of NF-KB and MAPK signalling. J. Mol. Med. 2017, 95, 1065-1076. [CrossRef]

36. Schmidt, M.W.; Baldridge, K.K.; Boatz, J.A.; Elbert, S.T.; Gordon, M.S.; Jensen, J.H.; Koseki, S.; Matsunaga, N.; Nguyen, K.A.; Su, S.; et al. General atomic and molecular electronic structure system. J. Comput. Chem. 1993, 14, 1347-1363. [CrossRef]

37. Mark Gordon's Quantum Theory Group. Available online: http://www.msg.ameslab.gov/GAMESS/GAMESS. html (accessed on 2 November 2020).

38. Mulliken, R.S. Electronic population analysis on LCAO-MO molecular wave functions. I. J. Chem. Phys. 1955, 23, 1833-1840. [CrossRef]

39. Na, H.K.; Surh, Y.J. Transcriptional regulation via cysteine thiol modification: A novel molecular strategy for chemoprevention and cytoprotection. Mol. Carcinog. 2006, 45, 368-380. [CrossRef] [PubMed]

40. Pande, V.; Sousa, S.F.; Ramos, M.J. Direct covalent modification as a strategy to inhibit nuclear factor- $\mathrm{kB}$. Curr. Med. Chem. 2009, 16, 4261-4273. [CrossRef] [PubMed]

41. Dinkova-Kostova, A.T.; Holtzclaw, W.D.; Cole, R.N.; Itoh, K.; Wakabayashi, N.; Katoh, Y.; Yamamoto, M.; Talalay, P. Direct evidence that sulfhydryl groups of Keap1 are the sensors regulating induction of phase 2 enzymes that protect against carcinogens and oxidants. Proc. Natl. Acad. Sci. USA 2002, 99, 11908-11913. [CrossRef] [PubMed]

42. Satoh, T.; Kosaka, K.; Itoh, K.; Kobayashi, A.; Yamamoto, M.; Shimojo, Y.; Kitajima, C.; Cui, J.; Kamins, J.; Okamoto, S.; et al. Carnosic acid, a catechol-type electrophilic compound, protects neurons both in vitro and in vivo through activation of the Keap1/Nrf2 pathway via S-alkylation of targeted cysteines on Keap1. J. Neurochem. 2008, 104, 1116-1131. [CrossRef] [PubMed]

43. Felemban, A.; Braguy, J.; Zurbriggen, M.D.; Al-Babili, S. Apocarotenoids involved in plant development and stress response. Front. Plant Sci. 2019, 10, 1168. [CrossRef] [PubMed]

44. Jia, K.-P.; Dickinson, A.J.; Mi, J.; Cui, G.; Kharbatia, N.M.; Guo, X.; Sugiono, E.; Aranda, M.; Rueping, M.; Benfey, P.N.; et al. Anchorene is an endogenous diapocarotenoid required for anchor root formation in Arabidopsis. bioRxiv 2018. [CrossRef]

45. Harrison, E.H.; dela Sena, C.; Eroglu, A.; Fleshman, M.K. The formation, occurrence, and function of beta-apocarotenoids: Beta-carotene metabolites that may modulate nuclear receptor signaling. Am. J. Clin. Nutr. 2012, 96, 1189S-1192S. [CrossRef] [PubMed]

46. Kopec, R.E.; Riedl, K.M.; Harrison, E.H.; Curley, R.W., Jr.; Hruszkewycz, D.P.; Clinton, S.K.; Schwartz, S.J. Identification and quantification of apo-lycopenals in fruits, vegetables, and human plasma. J. Agric. Food Chem. 2010, 58, 3290-3296. [CrossRef] [PubMed]

47. Gajic, M.; Zaripheh, S.; Sun, F.; Erdman, J.W., Jr. Apo-8'-lycopenal and apo-12'-lycopenal are metabolic products of lycopene in rat liver. J. Nutr. 2006, 136, 1552-1557. [CrossRef] [PubMed]

48. Zoccali, M.; Giuffrida, D.; Salafia, F.; Giofrè, S.V.; Mondello, L. Carotenoids and apocarotenoids determination in intact human blood samples by online supercritical fluid extraction-supercritical fluid chromatography-tandem mass spectrometry. Anal. Chim. Acta 2018, 1032, 40-47. [CrossRef]

49. Eroglu, A.; Harrison, E.H. Carotenoid metabolism in mammals, including man: Formation, occurrence, and function of apocarotenoids. J. Lipid Res. 2013, 54, 1719-1730. [CrossRef]

50. Cooperstone, J.L.; Novotny, J.A.; Riedl, K.M.; Cichon, M.J.; Francis, D.M.; Curley, R.W., Jr.; Schwartz, S.J.; Harrison, E.H. Limited appearance of apocarotenoids is observed in plasma after consumption of tomato juices: A randomized human clinical trial. Am. J. Clin. Nutr. 2018, 108, 784-792. [CrossRef]

51. Lobo, G.P.; Amengual, J.; Palczewski, G.; Babino, D.; von Lintig, J. Mammalian carotenoid-oxygenases: Key players for carotenoid function and homeostasis. Biochim. Biophys. Acta 2012, 1821, 78-87. [CrossRef] 
52. Kiefer, C.; Hessel, S.; Lampert, J.M.; Vogt, K.; Lederer, M.O.; Breithaupt, D.E.; von Lintig, J. Identification and characterization of a mammalian enzyme catalyzing the asymmetric oxidative cleavage of provitamin A. J. Biol. Chem. 2001, 276, 14110-14116. [CrossRef]

53. Amengual, J.; Lobo, G.P.; Golczak, M.; Li, H.N.; Klimova, T.; Hoppel, C.L.; Wyss, A.; Palczewski, K.; von Lintig, J. A mitochondrial enzyme degrades carotenoids and protects against oxidative stress. FASEB J. 2011, 25, 948-959. [CrossRef] [PubMed]

54. Pang, J.L.; Ricupero, D.A.; Huang, S.; Fatma, N.; Singh, D.P.; Romero, J.R.; Chattopadhyay, N. Differential activity of kaempferol and quercetin in attenuating tumor necrosis factor receptor family signaling in bone cells. Biochem. Pharmacol. 2006, 71, 818-826. [CrossRef] [PubMed]

55. Bharti, A.C.; Takada, Y.; Aggarwal, B.B. Curcumin (diferuloylmethane) inhibits receptor activator of NF- $\mathrm{kB}$ ligand-induced NF- $\mathrm{KB}$ activation in osteoclast precursors and suppresses osteoclastogenesis. J. Immunol. 2004, 172, 5940-5947. [CrossRef] [PubMed]

56. He, X.; Andersson, G.; Lindgren, U.; Li, Y. Resveratrol prevents RANKL-induced osteoclast differentiation of murine osteoclast progenitor RAW 264.7 cells through inhibition of ROS production. Biochem. Biophys. Res. Commun. 2010, 401, 356-362. [CrossRef]

57. Kim, S.J.; Kang, S.Y.; Shin, H.H.; Choi, H.S. Sulforaphane inhibits osteoclastogenesis by inhibiting nuclear factor-kB. Mol. Cells 2005, 20, 364-370.

58. Murakami, A.; Song, M.; Ohigashi, H. Phenethyl isothiocyanate suppresses receptor activator of NF- $\mathrm{kB}$ ligand (RANKL)-induced osteoclastogenesis by blocking activation of ERK1/2 and p38 MAPK in RAW264.7 macrophages. BioFactors 2007, 30,1-11. [CrossRef]

59. Shang, W.; Zhao, L.J.; Dong, X.L.; Zhao, Z.M.; Li, J.; Zhang, B.B.; Cai, H. Curcumin inhibits osteoclastogenic potential in PBMCs from rheumatoid arthritis patients via the suppression of MAPK/RANK/c-Fos/NFATc1 signaling pathways. Mol. Med. Rep. 2016, 14, 3620-3626. [CrossRef]

60. Calniquer, G.; Khanin, M.; Ovadia, H.; Linnewiel-Hermoni, K.; Stepensky, D.; Trachtenberg, A.; Levy, J.; Sharoni, Y. Combined effects of carotenoids and polyphenols in balancing the response of skin cells to UV irradiation. Eur. J. Nutr. 2020, submitted.

Publisher's Note: MDPI stays neutral with regard to jurisdictional claims in published maps and institutional affiliations.

(C) 2020 by the authors. Licensee MDPI, Basel, Switzerland. This article is an open access article distributed under the terms and conditions of the Creative Commons Attribution (CC BY) license (http://creativecommons.org/licenses/by/4.0/). 